\author{
ARTIGO \\ CO https://doi.org/10.22481/praxisedu.v15i36.5898
}

\title{
O FUTURO PODE TER MUITOS NOMES: SIGNIFICANDO O FOREGROUND
}

\author{
THE FUTURE CAN HAVE MANY NAMES: MEANING THE FOREGROUND
}

\author{
EL FUTURO PUEDE TENER MUCHOS NOMBRES: SIGNIFICANDO EL \\ FOREGROUND
}

\author{
Mônica Tessaro \\ Universidade do Oeste de Santa Catarina - Brasil \\ Lucí Teresinha Marchiori dos Santos Bernardi \\ Universidade Regional Integrada do Alto Uruguai e das Missões - Brasil
}

\begin{abstract}
Resumo: O presente artigo busca promover uma reflexão acerca da construção do conceito de foreground, da apropriação desse pelos pesquisadores brasileiros em seus trabalhos e das contribuições desse conceito para compreender questões contemporâneas que emergem do cotidiano escolar de nossas instituições. Constitui-se como estudo bibliográfico desenvolvido qualitativamente, recorte de uma dissertação de mestrado. Evidenciamos, então, que o conceito de foreground não é fechado, finalizado. Envolve uma teia complexa, configurado a partir das vivências que geram emoção e envolvem a imaginação, está em movimento. Nas pesquisas brasileiras emerge de forma tímida em termo de número de trabalhos, mas se coloca como inovador e pode se constituir como instrumento para diferentes campos do conhecimento, com pesquisas preocupadas com o indivíduo e sua inserção na teia social, que tratem das intenções, expectativas, aspirações e esperanças desse indivíduo, bem como das oportunidades sociais, políticas e econômicas que a sociedade oportuniza a ele.
\end{abstract}

Palavras chave: foregrounds; jovens; contemporaneidade.

\begin{abstract}
The present article seeks to promote a reflection about the construction of the concept of foreground, the appropriation of the same by the Brazilian researchers in their works and the contributions of this concept to understand contemporary issues that emerge from the school everyday of our institutions. A qualitative study was developed as a bibliographical study, cutting out a master's thesis. We then show that the concept of foreground is not closed, finalized. It involves a complex web, configured from the experiences that generate emotion and involve the imagination, is in movement. In the Brazilian researches, it emerges in a timid manner in terms of number of works, but it stands as an innovator and can be an instrument for different fields of knowledge, with researches concerned with the individual and their insertion in the social web, dealing with the intentions, expectations, aspirations and hopes of this individual, as well as of the social, political and economic opportunities that society offers him.
\end{abstract}

Keywords: foregrounds; gente joven; contemporaneidade. 
Resumen: El presente artículo busca promover una reflexión acerca de la construcción del concepto de forzos, de la apropiación del mismo por los investigadores brasileños en sus trabajos y de las contribuciones de ese concepto para comprender cuestiones contemporáneas que emergen del cotidiano escolar de nuestras instituciones. Se constituye como estudio bibliográfico desarrollado cualitativamente, recorte de una disertación de maestría. Evidenciamos entonces que el concepto de foreground no está cerrado, finalizado. Envolver una tela compleja, configurada a partir de las vivencias que generan emoción e involucra la imaginación, está en movimiento. En las investigaciones brasileñas emerge de forma tímida en término de número de trabajos, pero se coloca como innovador y puede constituirse como instrumento para diferentes campos del conocimiento, con investigaciones preocupadas con el individuo y su inserción en la red social, que traten de las intenciones, expectativas, aspiraciones y esperanzas de ese individuo, así como de las oportunidades sociales, políticas y económicas que la sociedad le permite a él.

Palabras clave: foreground; gente joven; contemporaneidade.

\section{Introdução}

O tema que mobilizou nossa investigação é a juventude e as diferentes questões que se colocam no cotidiano das escolas quando se busca compreender como os jovens se inserem nesse cotidiano: que relações estabelecem? Que significados atribuem? Como se engajam (ou não) nos processos educativos? Que motivos os levam a aprender?

A educação é considerada por muitos jovens como um meio para conseguir melhorar suas condições sociais. Ir à escola faz parte da educação formal, e é uma condição social seletiva, pois em muitos casos não frequentar a escola é estar condenado a subempregos. Em outros, ir à escola, mas não vivenciar os processos educativos, pode ser sinônimo de fracasso. Essas situações denunciam que a demanda dos jovens na escola toma múltiplas dimensões, alguns abandonam os estudos por alguma razão, enquanto outros continuam estudando com sonho de alcançar melhores condições sociais e empregos mais valorizados (FRANCO; NOVAES, 2001).

Ao pensar sobre o futuro, o jovem pode fazê-lo de modo utópico, imaginar uma vida alheia à sua é a realidade de muitos deles. Podem também pensar de modo realista, identificando em seu contexto as possibilidades para melhorar sua condição vivida. Independentemente do que o jovem deseja, sua perspectiva de futuro certamente trará implicações para sua aprendizagem. $\mathrm{Na}$ contemporaneidade, muito se discute sobre os motivos que levam os jovens aprenderem, esse tema tem ganhado força em diferentes áreas do conhecimento, mas, em especial, no campo psicológico, social e cultural. 
As inquietudes se transformaram em pesquisa desenvolvida no decorrer do Curso de Mestrado em Educação intitulada "Jovens olhares sobre a escola: vivências dos processos educativos a partir do background e do foreground" (TESSARO, 2018), que objetivou investigar em que medida os processos educativos desenvolvidos na escola favorecem a estruturação do foreground de jovens estudantes do nono ano do Ensino Fundamental. Este artigo é oriundo de um capítulo teórico da dissertação e trata fundamentalmente do conceito de foreground.

A âncora teórica do trabalho está nos pressupostos da Educação Matemática Crítica $(\text { EMC })^{1}$, cuja estrutura teórica é cunhada pelo pesquisador Ole Skovsmose, e refere-se a algumas preocupações (desafios) sobre educação matemática, educação e sociedade, que tem a ver com: diversidade na sociedade, (falta de) igualdade, (falta de) justiça social, (falta de) autonomia de estudantes, (falta de) autonomia de professores, função socioeconômica da educação matemática e função socioeconômica da matemática (SKOVSMOSE, 2011).

Consideramos que tais desafios não são exclusividades da Matemática, ao contrário, chegam à educação de forma geral, nas diferentes áreas do conhecimento, o que nos inspira a pensar a questão da juventude no âmbito da escola à luz de conceitos da EMC. Assim, colocamos em tela um dos seus conceitos fundantes: o foreground.

Pelo foreground de uma pessoa, Skovsmose (1994) entende as oportunidades que a situação social, econômica, política e cultural proporciona a ela. Porém, não as oportunidades como elas poderiam existir em qualquer forma objetiva, mas como essas oportunidades são sentidas por uma pessoa, ou seja, pode-se dizer que oforeground é da ordem da subjetividade, do desejo, da ordem inconsciente, isso psicanaliticamente falando, pois ele expressa expectativas, aspirações, esperanças, sonhos, desejos, anseios e medos.

O presente trabalho, um estudo bibliográfico desenvolvido qualitativamente, tem por objetivo apresentar uma revisão crítica de literatura acerca da construção do conceito de foreground e a apropriação do conceito pelos pesquisadores brasileiros em seus trabalhos, explicitar em que medida tal lente teórica pode colaborar com os pesquisadores ao examinarem questões contemporâneas que emergem do cotidiano escolar de nossas instituições.

\footnotetext{
${ }^{1}$ A ideia de Educação Matemática Crítica (EMC) emerge na década de 1970, é difundida inicialmente pelos trabalhos realizados por Marilyn Frankenstein e Arthur Powell nos Estados Unidos e posteriormente publicada nos trabalhos desenvolvidos pelo dinamarquês Ole Skovsmose, inspirado teoricamente na Pedagogia Freiriana e na Teoria Crítica da Escola de Frankfurt.
} 


\section{A construção do conceito de foreground}

O conceito de foreground $^{2}$ foi evoluindo na medida em que Skovsmose foi se inserindo no campo da educação crítica, realizando pesquisas, principalmente, com crianças e jovens que se encontravam em situações de risco. O autor inaugurou em 1994 a descrição do que para ele corresponde ao foreground e incrementou nos anos seguintes (2005, 2006, 2011, 2012, 2014). Sendo assim, coloca-se em tela a estruturação do conceito de foreground nas referidas obras.

Em 1994, Skovsmose realiza uma discussão sobre a aprendizagem significativa, nomeando de aprendizagem como uma ação, que, para o autor, ocorre quando o indivíduo participa de uma atividade tendo como objetivo aprender algo. Por exemplo, uma criança realizando uma atividade escolar que envolve a montagem de um relógio, ao colar os ponteiros e números à atividade poderia se caracterizar como uma aprendizagem se houvesse o interesse em desenvolver algum entendimento sobre as horas. Mas esta atividade não se caracterizaria uma aprendizagem como uma ação se a criança não prestasse atenção nas peças e mexesse os ponteiros e números de forma distraída. Consequentemente, a aprendizagem não é vivenciada como uma ação se o indivíduo desempenha uma tarefa de forma desatenta, mas sim se seu propósito é aprender algo.

Para Skovsmose (1994), ação envolve motivos, desejos e intenções. Nesse sentido, ações são sistemas guiados pelos desejos. E desejos não surgem por acaso. Os desejos de um indivíduo são formados através de seu background e foreground. No entanto, Skovsmose nada escreveu sobre o conceito de background nesse período.

$\mathrm{Na}$ primeira configuração do conceito de foreground, o autor o define como sendo as possibilidades que o contexto disponibiliza aos indivíduos para que as perceba e as tome como sendo suas. Assim sendo, o foreground estaria relacionado aos motivos que geram a aprendizagem, ou seja, os indivíduos aprendem se tiverem motivos para isso. Skovsmose (1994) critica os currículos impostos pelo Estado, segundo o autor, os foregrounds dos alunos não são considerados, podendo resultar em fatalidades educacionais, indicados nas seguintes afirmações: eu não sou capaz; não sou bom na escola; ou, eu tenho que participar e realizar as tarefas, mas não sei por que.

\footnotetext{
${ }^{2}$ Localiza-se na fenomenologia de Kant, do Eu Transcendental que supõe as categorias a priori de tempo e espaço. Em Husserl se localiza na fenomenologia da intencionalidade. Em Habermas, nas discussões do conhecimento e interesse. Em Freire, nos conhecimentos prévios do educando, sobre leitura de mundo e leitura da palavra. O que se destaca é o debate do foreground, mais tarde cunhado por Skovsmose.
} 
Em 2005, Skovsmose discute sobre as políticas de obstáculos para a aprendizagem e suas inferências no contexto social dos alunos, detalhando a relação entre o contexto social e o foreground de uma pessoa. Para ilustrar, o autor relata uma vivência que teve na África do Sul durante o regime de apartheid. Nesse período, o sistema político controlava o sistema educacional, gerando, assim, o controle da mente dos indivíduos, a mensagem da educação na época era "igualdade não é para negros".

Durante o comando do governo, muitos estudos foram realizados com o objetivo de esclarecer o baixo desempenho escolar dos estudantes negros. Skovsmose (2005), destaca que eram estudos realizados por pesquisadores brancos sobre o desempenho escolar dos negros. Com caráter visivelmente racista, os pesquisadores apontavam que os negros não aprendiam devido à sua estrutura biológica estabelecida a milhares de anos atrás. Nada foi considerado sobre a estrutura da escola, muito menos com a política do regime de apartheid. Nada poderia ser feito, pois, as crianças herdaram de seus antepassados o mau desempenho escolar. Em resumo, o rendimento escolar estava diretamente ligado à cor da pele.

Enquanto tais pesquisas demonstravam um tipo clássico de racismo, outras apontavam para um racismo chamado de progressivo. As pesquisas progressivas defendiam que o mau desempenho escolar se dava através dos aspectos sociais das crianças negras. $\mathrm{O}$ estudo aponta para a cultura familiar e, em particular, ao papel autoritário que o pai exercia sobre as crianças, anulando a criatividade dos filhos. Assim, novamente o baixo desempenho escolar nada tinha a ver com os fatores genéticos, nem a estrutura escolar, era a estrutura familiar o fator que explicava o fracasso dos alunos negros.

No entanto, ao visitar escolas da África do Sul, Skovsmose (2005), observa as condições das escolas: janelas faltando; portas quebradas; ausência de instalações elétricas; a existência de um buraco no telhado - talvez alguém removeu as telhas acreditando que sua casa necessitava mais delas do que a própria escola. A escola era um local onde alunos e professores gostariam de abandonar o mais rápido possível. Para o autor, tudo era muito óbvio, não era a cor da pele, nem a atitude dominante dos pais os responsáveis pelo baixo rendimento escolar, mas as condições pelas quais eram tratadas pelo regime do apartheid. $\mathrm{Ou}$ ainda, o buraco no telhado da escola.

A partir dessa vivência Skovsmose (2005), aprofunda suas reflexões sobre a relação entre o foreground e o contexto social de um indivíduo. $\mathrm{O}$ autor retoma essa discussão em 2007 para apresentar a ideia de um foreground arruinado. A perspectiva dos alunos negros da África do Sul não oferecia possibilidades de futuro, nesse caso, seus foregrounds estavam 
arruinados. As vagas de trabalho tinham como requisito um bom desempenho educacional, principalmente na área de matemática, por isso, não eram destinados aos negros. As próprias pesquisas demonstravam isso, visto que a escola nada podia fazer para auxiliar, pois a dificuldade era resquício genético ou cultural.

Quando a sociedade e as políticas de aprendizagem não oportunizam de maneira igualitária a educação, acabam obstruindo os estímulos para aprendizagem. Dessa maneira, um foreground arruinado é uma forma de impedir a aprendizagem, ou seja, o problema nem sempre está situado no buraco do telhado. Outro aspecto explorado por Skovsmose (2011), apresenta relações entre o background e foreground. Retomamos aqui o que o autor entende por foreground. Está relacionado às perspectivas futuras de uma pessoa, inclui o modo de como ela interpreta suas vivências, tais vivências incluem suas realizações e seus desejos, bem como as barreiras e frustrações que o indivíduo vivenciará em sua vida. Desta forma, o background gera tendências e propensões ao foreground de um indivíduo, mas é importante destacar: um background não determina um foreground, apesar das relações, tem um fator que os diferencia.

O background de um indivíduo se refere às suas vivências que estão, de algum modo, congeladas no pretérito. Por outro lado, o futuro de alguém pode englobar muitas possibilidades e interpretações. Foreground pode fazer menção a muitas possibilidades e, portanto, pode ser considerado como uma entidade flexível e múltipla. Portanto, nem as vivências passadas, nem os horizontes futuros de um indivíduo podem ser considerados entidades homogêneas, inflexíveis e determinantes (SKOVSMOSE, 2011).

Ainda assim, não podemos descartar o background de um indivíduo, ele deve ser levado em consideração para se entender algumas situações. Para melhor exemplificar isso, Skovsmose (2011), relata que em 2002 algumas investigações indicaram que em média 70\% das crianças palestinas e $30 \%$ das crianças israelenses vivenciaram traumas relacionados com a situação de guerra. Ao considerarmos a educação de tais crianças, nunca devem ser esquecidas tais vivências, pois os momentos dramáticos de suas vidas também fazem parte de suas condições de aprendizagem. É verdade que as perspectivas de futuro não são quantificadas estatisticamente, mas os obstáculos, bem como os desejos e expectativas que tais crianças irão vivenciar, serão consideravelmente diferentes de outras crianças que não vivem em situações de guerra. Desta forma, concordamos com Skovsmose (2011), quando afirma que o contexto social de uma pessoa pode contribuir na configuração de um 
foreground forte ou arruinado, mas é importante ressaltar que um contexto social arruinado pode favorecer um foreground forte através da superação e autonomia do sujeito.

Outro elemento que Skovsmose (2012), apresentou para discutir a questão do foreground arruinado: relata uma vivência que teve com jovens que frequentavam uma escola situada na periferia de Barcelona, na Espanha. Sua intenção era investigar o foreground daqueles jovens. Pediu para que os jovens fechassem os olhos e imaginassem como gostariam de estar em dez anos se conseguissem conquistar os seus sonhos. O objetivo era dar voz aos jovens para que contassem sobre seus sonhos. Passados os dez minutos, os alunos começaram a contar sobre seus sonhos, falaram sobre as profissões que queriam seguir. Skovsmose ficou surpreso ao ouvir sobre profissões escolhidas pelos jovens, que, segundo o autor, são pouco prestigiadas pela sociedade, tais como: mecânico, cabeleireiro, pedreiro. Logo pensou que os jovens não haviam entendido a atividade proposta, mas interpretou de outra forma. Para o autor, sonhar pode ser doloroso, por isso, os jovens preferiram manter os pés no chão.

A expressão sonhos em gaiola foi uma metáfora criada pelo autor para difundir a ideia de que um foreground arruinado pode se transformar em um obstáculo para a aprendizagem, e, mais do que isso, pode aprisionar os sonhos dos excluídos. Consideramos essa metáfora como uma chave de leitura para entender a sociedade contemporânea. A escola com suas grades, muros, horários e currículo pré-estabelecidos é considerada uma gaiola. Os professores também possuem suas grades. A sociedade de consumo é uma gaiola, pois o capitalismo é uma gaiola. Não somos livres no capitalismo. Vivemos em uma cultura que não nos oportuniza a vivenciar a liberdade.

Para Bauman (1998), o significado dessa afirmação é clara, o capital é a única entidade que se move livremente e, certamente, as grandes indústrias podem mover-se como quiserem através dele. O capital não está em um ambiente físico específico e não tem nenhuma obrigação com as pessoas ou até mesmo com a sociedade. Onde ele está e o que está produzindo é determinado pelas pessoas, que, privadas da liberdade, trabalham para terem seu sustento. O movimento permanente do capital é um elemento definidor da sociedade contemporânea, e isso significa engaiolar sonhos.

Frankl (1987), criador da logoterapia, usa a metáfora campo de concentração para caracterizar a sociedade. Para ele, “[...] vivemos em uma sociedade que busca virtualmente se satisfazer, ou pelo menos se propõe a gratificar cada uma das necessidades humanas, mas se esquece, essencialmente, de seu sentido" (FRANKL, 1987, p. 55). O autor defende que a atual sociedade cria necessidades, porém, a questão do sentido permanece insatisfeita, ou seja, nos 
encontramos em um contexto marcado pela crise individualista apegada ao consumismo, ao prazer e ao poder.

O uso campo de concentração como metáfora para compreender a sociedade contemporânea se dá pelo fato de que em ambos os casos se caracterizam um tipo de organização do espaço privado, um controle do tempo através do trabalho, a vigilância como instrumento de controle e autocontrole, promovendo a dificuldade de encontrar sentido ou atribuir significado às coisas e à própria vida (FRANKL, 1987).

O capitalismo pode incluir pessoas no fluxo da informação e ao acesso de bens e produtos. Mas o capitalismo pode também, de maneira bem mais brutal, excluir e engaiolar sonhos. No passado, o capitalismo tinha caráter exploratório, no entanto, na contemporaneidade sua evolução se dá através da exclusão, provocando o aumento da miséria e pobreza humana. Este é um lembrete do fato de que engaiolar sonhos faz parte da ordem global da contemporaneidade (BAUMAN, 2004).

A partir da metáfora sonhos em gaiola, Skovsmose (2012), chega à conclusão que o foreground compreende uma complexa combinação que envolve dois aspectos. Um aspecto é externo, relacionado ao contexto social do indivíduo, formado pelas oportunidades e obstáculos que os parâmetros sociais políticos e culturais podem lhe fornecer. Por outro lado, o foreground também diz respeito ao aspecto subjetivo do indivíduo. Nessa sequência, constitui-se por meio das vivências de um indivíduo e de como ele as interpreta. Na condição subjetiva, o foreground abarca desejos, sonhos, intenções, percepções, anseios, angústias e medos de um indivíduo. Assim sendo, é constituído pela combinação dos fatores internos e externos.

Explorando o aspecto subjetivo Skovsmose (2014), discute sobre o papel da imaginação na estruturação do foreground. Assim sendo, poderia incluir no foreground o que poderia acontecer, o que poderia ser esperado, ser temido e ser conquistado. Porém, a humanidade ainda não definiu um limite no qual termina a realidade e começa a fantasia. Chega-se à conclusão de que o conceito não é totalmente fechado, finalizado. Envolve uma teia complexa, configurado a partir das vivências que geram emoção e envolvem a imaginação, um conceito em movimento que pode contribuir de sobremaneira com pesquisas preocupadas com o indivíduo e sua inserção na teia social, que tratem das intenções, expectativas, aspirações e esperanças desse indivíduo, bem como das oportunidades sociais, políticas e econômicas que a sociedade oportuniza a ele. De forma especial, pesquisas que se preocupam com a educação, com os processos educativos, com nossos estudantes. 


\section{Algumas pesquisas inspiradas pelo foreground}

Consideramos importante conhecer pesquisas já publicadas que abordam em sua discussão o conceito de foreground, para compreendermos a dimensão que tal teoria tem entre os pesquisadores brasileiros.

Grande parte das pesquisas que envolvem o conceito de foreground foi publicada em língua inglesa, que é justificado pelo fato de ser a segunda língua do dinamarquês Ole Skovsmose. No entanto, como o autor interessou-se pelo Brasil e atualmente é professor da Universidade Estadual Paulista Júlio de Mesquita Filho (UNESP), publicou alguns estudos, em parceria com outros autores, escritos em Língua Portuguesa. Também tem sido inspiração a jovens pesquisadores na elaboração de suas pesquisas.

Com o intuito de conhecer mais sobre a estruturação do conceito foreground, realizamos uma busca bibliográfica no Banco de Teses e Dissertações da Capes e na Base Scientific Eletronic Library Online (SciELO), sobre estudos que foram publicados em Língua Portuguesa. Os termos utilizados para a busca foram: foreground, foregrounds, perspectivas de futuro, estudantes/aluno e background. Os estudos que abordam o tema em questão foram salvos e lidos, os quais serviram de base para consultas.

Quadro 1 - Desenvolvendo o conceito de foreground no Brasil

\begin{tabular}{|c|c|c|c|}
\hline Título da obra & Autores & $\begin{array}{c}\text { Ano de } \\
\text { Publicação }\end{array}$ & Local de Publicação \\
\hline $\begin{array}{l}\text { Antes de dividir temos que somar: } \\
\text { "entre-vistando" foregrounds de } \\
\text { estudantes indígenas }\end{array}$ & $\begin{array}{c}\text { Ole Skovsmose; } \\
\text { Helle Alrø; } \\
\text { Paola Valero; } \\
\text { Pedro Paulo Scandiuzzi; } \\
\text { Ana Paula Silvério }\end{array}$ & 2009 & $\begin{array}{l}\text { Revista Bolema, } \\
\text { Rio Claro } \\
\text { (Artigo) }\end{array}$ \\
\hline $\begin{array}{l}\text { Etnomatemática, educação matemática } \\
\text { crítica e pedagogia dialógico-libertadora: } \\
\text { contextos e caminhos pautados na } \\
\text { realidade sociocultural dos alunos }\end{array}$ & $\begin{array}{c}\text { Jaqueline Ferreira dos } \\
\text { Reis }\end{array}$ & 2010 & $\begin{array}{c}\text { Banco de Teses e } \\
\text { Dissertações da Capes } \\
\text { (Dissertação) }\end{array}$ \\
\hline $\begin{array}{c}\text { A aprendizagem matemática em uma } \\
\text { Posição de Fronteira: foregrounds e } \\
\text { intencionalidade de estudantes de uma } \\
\text { favela brasileira }\end{array}$ & $\begin{array}{c}\text { Ole Skovsmose; } \\
\text { Pedro Paulo Scandiuzzi; } \\
\text { Paola Valero; } \\
\text { Helle Alrø }\end{array}$ & 2012 & $\begin{array}{l}\text { Revista Bolema, } \\
\text { Rio Claro } \\
\text { (Artigo) }\end{array}$ \\
\hline $\begin{array}{l}\text { Educação matemática na escola indígena } \\
\text { sob uma abordagem crítica }\end{array}$ & $\begin{array}{l}\text { Luci dos Santos } \\
\text { Bernardi; } \\
\text { Ademir Donizeti } \\
\text { Caldeira }\end{array}$ & 2012 & $\begin{array}{l}\text { Revista Bolema, } \\
\text { Rio Claro } \\
\text { (Artigo) }\end{array}$ \\
\hline $\begin{array}{l}\text { Foregrounds e Matemática: você tem } \\
\text { fome de quê? }\end{array}$ & Denival Biotto Filho & 2014 & $\begin{array}{l}\text { Revista Perspectivas em } \\
\text { Educação Matemática }\end{array}$ \\
\hline $\begin{array}{l}\text { Quem não sonhou em ser um jogador de } \\
\text { futebol? Trabalho com projetos para } \\
\text { reelaborar foregrounds }\end{array}$ & Denival Biotto Filho & 2015 & $\begin{array}{c}\text { Banco de Teses e } \\
\text { Dissertações da Capes } \\
\text { (Tese) }\end{array}$ \\
\hline
\end{tabular}

Fonte: Elaboração das autoras (2017). 
O artigo de Skovsmose et al. (2009), é uma tradução ao português do original Before you divide, you have to add: "interviewing” indian students foregrounds, com autoria de Ole Skovsmose, Helle Alrø, Paola Valero, em colaboração com Ana Paula Silvério e Pedro Paulo Scandiuzzi (2007), publicado no The Montana Mathematics Enthusiast (Monograph: International Perspectives on Social Justice in Mathematics Education), Missoula (USA): University of Montana, p. 151-168. A tradução do mesmo artigo para o espanhol foi publicada na Revista Latinoamericana de Etnomatemática 1 (2) (2008, p. 111-136). Pedro Paulo Scandiuzzi foi quem traduziu ao português e Bharath Sriraman permitiu a divulgação do texto em Língua Portuguesa em 2009. Foi a partir desta tradução que os autores decidiram manter os termos foreground e background em inglês e itálico. Para eles, o foreground não tem expressão única, podendo ser entendido tanto como perspectiva de futuro, quanto as expectativas ao devir. E o conceito de background, de certa forma, já está incorporado à Língua Portuguesa.

Skovsmose et al. (2009), narram uma pesquisa que realizaram com estudantes indígenas brasileiros, tendo como objetivo investigar as percepções dos alunos sobre suas possibilidades educacionais. É interessante observar os diferentes significados que os alunos atribuíram à educação, em especial, à educação matemática.

Inicialmente, os estudantes atribuíram à matemática um significado instrumental. $\mathrm{Ou}$ seja, aprender matemática tinha a ver com a perspectiva de futuro, neste caso, com a melhoria das condições de vida. O significado da matemática é um importante fator para foregrounds de alunos que desejam melhores condições sociais. Para os indígenas, a educação poderia ser o principal caminho para emigrarem da aldeia. No entanto, os alunos apontaram o desejo de ingressarem no ensino superior e, posteriormente, retornar à aldeia e ajudá-la.

Ao afirmarem sobre a importância de continuar os estudos para ajudar a aldeia, é possível relacionar a ideia de solidariedade. Entretanto, os autores perceberam diferentes modos de atribuição de significado à Matemática: o instrumental, o cotidiano, aquele vinculado ao trabalho ou prática futura, o sociopolítico ou o significado voltado ao exercício de uma cidadania crítica. Estes tipos de significação estão inter-relacionados. Isso exemplifica a característica múltipla de foregrounds.

Reis (2010), em sua pesquisa de mestrado investigou sobre as possibilidades de articulação entre o conhecimento matemático e as realidades sociais, políticas, culturais e econômicas, através de atividades que objetivavam valorizar os contextos de vida dos alunos. 
A autora considera em seu estudo o background e oforeground dos alunos que frequentavam o primeiro e segundo ano do Ensino Médio de uma escola de Goiânia.

Em sua pesquisa Reis (2010), evidencia que o background e o foreground dos alunos devem ser mais explorados pelos professores para oportunizar a aprendizagem significativa, despertando no aluno motivações e posicionamento crítico frente a sua realidade, buscando a realização de seus sonhos. A autora destaca ainda que é preciso valorizar vivências cotidianas, o contexto do aluno e sua cultura, pois ações, comportamentos e perspectivas de futuro fazem parte do cotidiano do aluno, podendo ser mediadas no espaço escolar.

A escola é um local de mediação, que é capaz de oportunizar ao aluno relacionar-se com o outro no contexto da diversidade cultural, com os conhecimentos historicamente construídos, tendo como principal função social a inserção dos cidadãos em espaços que visem formar a conscientização e reflexão crítica. É na escola que os jovens podem encontrarse diante de uma posição de fronteira entre as coisas que gostam de fazer e as que não gostam ou não se identificam. Sobre o a posição de fronteira, Skovsmose et al. (2012) estudaram foregrounds de cinco estudantes moradores de uma favela brasileira.

Nesta obra, os autores apresentam a ideia de posição de fronteira, que se refere a uma posição em que o indivíduo pode ver suas próprias condições de vida em relação a outras possibilidades de vida. Neste lugar há o contato e o conflito entre pessoas de diferentes mundos culturais. A posição de fronteira tem um caráter duplo, pois ao passo que promove a experiência da diversidade, assim como a experiência de que algumas opções estão fora do alcance de algumas pessoas.

Os autores pediram aos jovens entrevistados que contassem como se imaginavam no futuro. Em seguida, motivaram os jovens a refletirem sobre os motivos existentes para aprenderem Matemática, tanto em termos de profissão, quanto ao acesso a um curso superior. Os entrevistados falaram sobre o sentimento de discriminação que sentem por viverem em um bairro pobre, demonstrando o desejo de iniciarem uma vida nova fora da favela. Encaram a educação como uma importante chave para mudarem de vida, no entanto, não atribuem nenhuma relevância de se estudar matemática. Apesar do desejo de mudarem de vida, os foregrounds dos jovens demonstram incertezas, apontam o contexto social em que vivem como um espaço limitador de seus sonhos.

Identificaram na fala dos alunos uma clara posição de fronteira entre o espaço marginalizado em que vivem e a cultura dominante. Desta forma, os alunos tiveram a oportunidade de refletir sobre as possibilidades de futuro se ultrapassassem a linha de 
fronteira em que vivem e acessassem outros modos de vida. Tal exercício pode resultar em diferentes consequências aos foregrounds dos jovens. Por um lado, a educação pode ser considerada como uma possibilidade de ultrapassar fronteiras, por outro lado, os alunos vivenciam a dura realidade que existe na posição de fronteira, incluindo a divisão de classes sociais e a exclusão. Nesse sentido, a escola pode assumir diferentes papéis, oportunizar a abertura de novas experiências, ou pode aprisionar o sonho dos jovens em gaiolas, mantendoos em suas posições atuais.

Bernardi e Caldeira (2012), continuam nesse mesmo viés refletindo sobre o papel mediador da escola, mais especificamente de uma escola indígena localizada no oeste catarinense. Os autores colocam em tela os desafios da Educação Matemática na escola indígena, e analisam o foreground dos estudantes. É importante destacar que para discutir sobre a educação na escola indígena é preciso considerar a posição de fronteira dos alunos entre os saberes de seu povo e os saberes europeizados da escola.

Os autores destacam que, para refletir sobre a Educação Matemática dos estudantes indígenas, é necessário considerar que os motivos que os levam a aprenderem algo estão relacionados com o background e com o foreground desses estudantes, pois devemos considerar não somente as vivências pretéritas, mas, também, as suas perspectivas de futuro. Bernardi e Caldeira (2012), afirmam ainda que uma educação emancipatória adiciona algo no foreground do estudante indígena, e essas adições desempenham um importante papel. Se o foreground de um estudante indígena for arruinado, empobrece a educação significativa, aprisionando os indígenas em sala de aula, acentuando os processos de exclusão.

O conflito cultural também está presente na tese e em artigos publicados por Biotto Filho quando investiga o foreground de jovens em idade escolar que frequentam um projeto social de semiabrigo e intitulado Projeto Futebol. Biotto Filho (2014) desenvolveu um conjunto de atividades para compreender de que forma tais atividades poderiam contribuir na reelaboração do foreground dos jovens que vivem em condições de pobreza. Tinha como foco explorar o desejo dos jovens em se tornarem jogadores de futebol. Baseou-se na proposta de trabalho com projetos educacionais, envolvendo jogos, entrevistas, maquetes, gravação e edição de vídeos e conversas com profissionais convidados. Tudo isso foi analisado para identificar possíveis reelaborações no foreground dos jovens e em suas perspectivas de futuro.

As contribuições de Biotto Filho (2014), incluem a identificação e ampliação das características do conceito de foreground, aprofundas as reflexões sobre as relações entre o foreground de um indivíduo e seu contexto social, bem como discussões sobre as 
possibilidades da proposta de trabalho com projetos educacionais para a reelaboração de foregrounds. Biotto Filho (2015), orientado por Ole Skovsmose, possui várias produções publicadas em português e inglês, nas quais utiliza o conceito de foreground. $\mathrm{O}$ autor construiu sua tese a partir de 12 artigos científicos, nos quais aprofunda suas reflexões sobre o conceito de foreground, cunhado pelo seu orientador.

Para Biotto Filho (2015), o foreground de um indivíduo se estrutura através dos fatores sociais, econômicos, políticos e culturais. Considera que o local de nascimento possibilita a vivência de oportunidades ou obstáculos, definidos a partir de indicadores estatísticos, os quais podem caracterizar o acesso e o tempo de escolarização, o local de trabalho, o acesso ao lazer, à cultura, à segurança, à riqueza ou à pobreza.

Por outro lado, Biotto Filho (2015) não considera o foreground formado apenas por questões estatísticas e objetivas de ordem social, ele também se estrutura por intermédio de vivências e interpretações das possibilidades, desejos, sonhos, medos, tornando-se, assim, uma complexa relação entre os fatores externos e internos. Desta forma, os foregrounds são estruturados pelos diferentes valores subjetivos e objetivos que designam escolhas, intenções e gostos na vida dos jovens (SKOVSMOSE, 2012).

Portanto, todas as pesquisas que levam em consideração o conceito de foreground publicadas em português fazem referência aos esfarrapados do mundo, ou ao quarto mundo, anunciado por Castells $(1996)^{3}$. Todos os autores por hora citados possuem formação em Matemática e discutem o conceito de foreground sob o viés social. Certamente, esses profissionais foram influenciados pelo também matemático Ole Skovsmose.

Na dissertação "Jovens olhares sobre a escola: vivências dos processos educativos a partir do background e do foreground" (TESSARO, 2018), que deu origem ao presente artigo, o conceito de foreground demarcou o próprio objeto de pesquisa. Ela foi desenvolvida uma escola pública da cidade de Chapecó (SC), e buscou compreender se os processos educativos oferecidos pela escola favoreciam a estruturação do foreground dos jovens. Cabe destacar que esse trabalho não tem origem na formação Matemática, mas inspiração, pois tem berço na Psicologia.

Analisando encontrar uma forma para que possamos alcançar uma mudança educacional, nos baseamos em Skovsmose (2006), e Freire (2015), através de suas

Castells (1996) emprega o termo Quarto Mundo, criado por processos globalizados de exclusão social, econômica e política. Também emprega a metáfora "a conexão perversa", para caracterizar a organização capitalista que busca tirar tirou vantagem de sua condição para promover o desenvolvimento da economia do crime global. 
concepções da educação crítica e democrática, utilizamos destes estudos para nos auxiliar na compreensão não apenas do conteúdo didático, mas, sobretudo, do contexto em que vivemos, dos constantes movimentos contemporâneos que nos envolvem.

O trabalho teve como pretensão investigar a partir do conceito de foreground, ou seja, dos sentimentos, sonhos, expectativas e desejos a relação que os jovens dos anos finais do Ensino Fundamental estabelecem entre as vivências dos processos educativos e suas perspectivas de futuro. Concebe que oforeground se constitui de diferentes maneiras, por essa razão os jovens apresentam múltiplos foregrounds. Os resultados nos mobilizam a debater e refletir sobre a falta de um ambiente que preconize o real objetivo da escola na preparação de jovens para alcançarem suas perspectivas de futuro.

No âmbito da escola e no contexto do tema da pesquisa que originou essa reflexão, é possível inferir que assim como os foregrounds são estruturados de diferentes formas, as dificuldades e facilidades que os jovens irão enfrentar na vida também acontecem na multiplicidade, seus modos de agir, principalmente no que diz respeito à escolaridade, acontecem de diferentes maneiras. Para compreender as prioridades e comportamentos na escola é preciso entender os motivos que os jovens têm de aprenderem algo. Os jovens são capazes de aprender qualquer coisa se tiverem motivos para fazê-lo. Pensando dessa forma e concordamos com Biotto Filho (2015), a escola precisa adicionar algo no foregrounds dos jovens.

Em Freire (2015), a educação é conscientização que permite o educando transformar a realidade em que vive, assim como, para Skovsmose (2004), a educação se dá pela ação. Todavia, a aprendizagem precisa fazer sentido para o jovem para que esse possa intervir no mundo vivido, dado que "[...] se os educandos não puderem ver qualquer perspectiva no que eles estão fazendo, então não podemos esperar qualquer participação significativa deles." (SKOVSMOSE, 2004, p. 117).

Eu vejo a aprendizagem como ação (não todos os tipos de aprendizagem, mas alguns). Em particular, estou interessado em situações onde os educandos entendam a possibilidade de estabelecer aprendizagem como ação e tenham a oportunidade de colocar suas intenções na aprendizagem. No entanto, estamos longe de todos os educandos terem a oportunidade de relacionar o conteúdo da aprendizagem ao seu foreground. (SKOVSMOSE, 2004, p. 111).

No decorrer da pesquisa tivemos a oportunidade de investigar a partir do conceito de foreground, ou seja, dos sentimentos, sonhos, expectativas e desejos a relação que os jovens dos anos finais do Ensino Fundamental estabelecem entre as vivências dos processos 
educativos e suas perspectivas de futuro. Partimos da ideia que foreground se constitui de diferentes maneiras, por essa razão os jovens apresentam múltiplos foregrounds.

As pesquisas aqui relatadas apontam para a importância de possibilitar o desenvolvimento do foreground dos estudantes, no sentido de refletir as práticas pedagógicas que estão sendo ofertadas aos alunos, permitindo-nos pensar criticamente sobre o contexto em que os jovens estão inseridos, tanto em relação ao contexto social, quanto escolar, demandando do professor um olhar voltado às múltiplas necessidades sociais, econômicas e afetivas, oferecendo-lhes possibilidades que possam estimular a autonomia cognitiva e pessoal através dos processos educativos.

\section{Considerações finais}

A partir dos estudos realizados por Skovsmose (1994, 2005, 2006, 2011, 2012, 2014) acerca da estruturação do foreground, é possível inferir que:

- a estruturação do foreground tem alguma coisa a ver com o contexto e a posição social do sujeito;

- para compreender um foreground é importante levar em consideração a singularidade e as vivências de cada sujeito;

- o foreground está associado ao significado que os sujeitos atribuem à sua própria singularidade;

- o foreground é também da ordem do desejo e a atividade afetiva, por isso mobiliza os sujeitos de forma positiva ou negativa;

- o foreground pode ser considerado como principal elemento para compreendermos as ações de um sujeito.

Paulo Freire nos ajuda a compreender melhor a estruturação do foreground quando nos lembra que o ser humano é um portador de desejos. É um ser movido de desejos que se relaciona com outros humanos também portadores de desejos, sendo assim, é um ser sociável, que ocupa um lugar na sociedade, um lugar singular e único, pois tem uma história de vida, interpreta o mundo à sua maneira, atribui sentido a esse mundo, à posição que nele ocupa, às suas relações e à sua própria singularidade.

A escola é entendida como um espaço que deve oportunizar a mediação da aprendizagem, podendo desempenhar um importante papel na inclusão e exclusão social, o que pode aprisionar os sonhos dos jovens em gaiolas. Um foreground forte oferece motivos 
para o indivíduo aprender e um foreground arruinado gera obstáculos para aprendizagem. Sendo assim, as vivências hodiernas de um indivíduo não determinam um foreground, no entanto, devem ser levadas em conta.

Sobre as pesquisas que identificamos que abordam o tema, nos explicitam o panorama de uma teoria que ainda é emergente e que trata de um conceito inovador. Acreditamos que é uma lente teórica importante para colaborar com os pesquisadores ao examinarem questões contemporâneas que emergem do cotidiano escolar de nossas instituições, pensando em foreground de crianças, de jovens, de professores, de pais e de toda comunidade escolar. Para além da Matemática, se constitui instrumento para diferentes campos do conhecimento, quando nossas preocupações com educação e sociedade tenham a ver, efetivamente, com o tecido social, com a função sociopolítica de cada campo.

Considerando a nossa pesquisa com o tema juventude, especialmente, queremos evidenciar que assim como os foregrounds são estruturados de diferentes formas, as dificuldades e facilidade que os jovens irão enfrentar na vida também acontecem na multiplicidade, seus modos de agir, principalmente no que diz respeito à escolaridade, acontecem de diferentes maneiras. Para compreender as prioridades e comportamentos na escola é preciso entender os motivos que os jovens têm de aprenderem algo. Os jovens são capazes de aprender qualquer coisa se tiverem motivos para fazê-lo. Pensando dessa forma e concordando com Biotto Filho (2015), a escola precisa adicionar algo no foregrounds dos jovens.

Por fim, acreditamos que nosso trabalho pode contribuir com elementos para o debate acerca do sentido dos processos educativos para os jovens contemporâneos, para o professor refletir sobre a valorização do contexto dos alunos, contribuindo assim com a ruptura de uma educação neoliberal voltada ao mercado de trabalho. Destacamos essa ruptura de grande importância, pois objetiva a formação significativa por meio da construção interativa entre jovens, escola e contexto social, proporcionando-os um desenvolvimento crítico-reflexivo, denominado foreground, que é o objeto principal na construção das perspectivas de futuro dos jovens alunos.

\section{REFERÊNCIAS}

BAUMAN, Zygmunt. Amor líquido: sobre a fragilidade dos laços humanos. Rio de Janeiro: Zahar, 2004.

BAUMAN, Zygmunt. O mal-estar da pós-modernidade. Rio de Janeiro: Jorge Zahar, 1998. 
BERNARDI, Luci dos Santos; CALDEIRA, Ademir Donizeti. Educação matemática na escola indígena sob uma abordagem crítica. Bolema, Rio Claro, v. 26, n. 42, p. 409-432, abr. 2012.

BIOTTO FILHO, Denival. Foregrounds e Matemática: você tem fome de quê? Perspectivas da Educação Matemática, Campo Largo, v. 7, n. 14, p. 237-247, 2014.

BIOTTO FILHO, Denival. Quem não sonhou em ser um jogador de futebol? Trabalho com projetos para reelaborar foregrounds. 2015. $234 \mathrm{f}$. Tese (Doutorado em Educação Matemática) - Universidade Estadual Paulista, Rio Claro, 2015.

CASTELLS, Manuel. Fluxos, redes e identidades: uma teoria crítica da sociedade informacional. In: CASTELLS, Manuel et al. Novas perspectivas críticas em educação. Porto Alegre: Artes Médicas, 1996. p. 4-32.

D’AMBRÓSIO, Ubiratan. Etnomatemática: arte ou técnica de explicar e conhecer. São Paulo: Ática, 1990.

FRANCO, Maria Laura Barbosa; NOVAES, Gláucia Torres Franco. Os jovens do ensino médio e suas representações sociais. Cadernos de Pesquisa, São Paulo, n. 112, p. 167-183, mar. 2001.

FRANKL, Viktor E. Em busca de sentido: um psicólogo no campo de concentração.

Tradução de Walter Schlupp e Carlos Aveline. Porto Alegre: Sulina; São Leopoldo: Sinodal, 1987.

FREIRE, Paulo. Pedagogia da autonomia: saberes necessários à prática educativa. 50. ed. Rio de Janeiro: Paz e Terra, 2015.

REIS, Jaqueline Ferreira dos. Etnomatemática, educação matemática crítica e pedagogia dialógico-libertadora: contextos e caminhos pautados na realidade sociocultural dos alunos. 2010. 147 f. Dissertação (Mestrado em Educação em Ciências e Matemática) - Universidade Federal de Goiás, Goiânia, 2010.

SKOVSMOSE, Ole et al. An invitation to critical mathematics education. Rotterdam: Sense Publishers, 2011.

SKOVSMOSE, Ole et al. Etnomatemática: papel, valor e significado. São Paulo: Zouk, 2004.

SKOVSMOSE, Ole. Foreground dos educandos e a política de obstáculos para aprendizagem. In: RIBEIRO, José Pedro Machado et al. (Org.). Etnomatemática: papel, valor e significado. 2. ed. Porto Alegre: Zouk, 2006. p. 103-122.

SKOVSMOSE, Ole. Foregrounds: opaque stories about learning. Rotterdam: Sense Publishers, 2014.

SKOVSMOSE, Ole. Students' foregrounds: Hope, despair, uncertainty. Pythagoras, [s.1.], v. 33, n. $2,2012$.

SKOVSMOSE, Ole. Towards a philosophy of critical mathematics education. Dordrecht: Kluwer Academic Publishers, 1994. 
SKOVSMOSE, Ole et al. Travelling through education: uncertainty, mathematics responsibility. Rotterdam: Sense Publishers, 2005.

SKOVSMOSE, Ole et al. A aprendizagem matemática em uma Posição de Fronteira: foregrounds e intencionalidade de estudantes de uma favela brasileira. Bolema, Rio Claro, v. 26, n. 42, p. 231-260, abr. 2012.

SKOVSMOSE, Ole et al. Antes de dividir temos que somar: "entre-vistando" foregrounds de estudantes indígenas. Bolema, Rio Claro, n. 34, p. 237-262, 2009.

TESSARO, Mônica. Jovens olhares sobre a escola: vivências dos processos educativos a partir do background e do foreground. 2018. 166 f. Dissertação (Mestrado em Educação) Universidade Comunitária da Região de Chapecó, Chapecó, 2018.

\section{$\underline{\text { SOBRE AS AUTORAS }}$}

\section{Mônica Tessaro}

Doutoranda em Educação pelo Programa de Pós-Graduação da Universidade do Oeste de Santa Catarina (UNOESC). Mestre em Educação pelo Programa de Pós-Graduação da Universidade Comunitária da Região de Chapecó (UNOCHAPECO). Graduada em Psicologia pela UNOCHAPECO. Membro Linha de pesquisa Processos Educativos da UNOESC. Bolsista de da Coordenação de Aperfeiçoamento de Pessoal de Nível Superior Brasil (CAPES) - Código de Financiamento 001. Correio eletrônico: m_tessaro@unochapeco.edu.br

iD http://orcid.org/0000-0001-6744-9142

\section{Lucí Teresinha Marchiori dos Santos Bernardi}

Doutora em Educação Científica e Tecnológica e Mestre em Educação pela Universidade Federal de Santa Catarina (UFSC). Graduada em Matemática pela Universidade de Passo Fundo (UPF). Professora pesquisadora do Programa de Pós-graduação em Educação da Universidade Regional Integrada do Alto Uruguai e das Missões (URI/FW). Correio eletrônico: lucisantosbernardi@gmail.com

(iD) http://orcid.org/0000-0001-6744-9142

Recebido em: 29 de maio de 2018 Aprovado em: 21 de setembro de 2019 Publicado em: 03 de dezembro de 2019 